\title{
Antioxidant Activity and Mechanism of Protocatechuic Acid in vitro
}

\author{
Xican Li ${ }^{1{ }^{*}}$, Xiaozhen Wang ${ }^{1}$, Dongfeng Chen ${ }^{2}$, Shuzhi Chen ${ }^{1}$ \\ ${ }^{1}$ School of Chinese Herbal Medicin, Guangzhou University of Chinese Medicine, Guangzhou, \\ China \\ ${ }^{2}$ The State Key Laboratory of Pharmaceutical Biotechnology, Department of Biochemistry, \\ Nanjing University, Nanjing, China
}

Corresponding author: Xican Li, Prof., School of Chinese Herbal Medicine, Guangzhou University of Chinese Medicine, Guangzhou, China

Submission date: June 22, 2011; Acceptance date: July 30, 2011; Publication date: July 31, 2011

\section{Abstract:}

Background: Protocatechuic acid (PCA) is a natural phenolic acid widely distributed in plants and is considered as an active component of some traditional Chinese herbal medicines such as Cibotium barometz (L.) J.Sm, Stenoloma chusanum (L.) Ching, Ilex chinensis Sims. PCA was reported to possess various pharmacological effects which may be closely correlated with its antioxidant activities. However, the antioxidant of PCA has not been investigated systematically yet.

Methods: In the study, the antioxidant activities of protocatechuic acid were measured in vitro using various antioxidant assays including 1,1-diphenyl-2-picryl-hydrazyl (DPPH•), 2,2'-azino-bis (3-ethylbenzthiazoline-6-sulfonic acid) $\left(\mathrm{ABTS}^{+} \bullet\right.$, superoxide anion radicals $\left(\bullet \mathrm{O}_{2}{ }^{-}\right)$and hydroxyl radical $(\bullet \mathrm{OH})$ scavenging activity, ferric ions $\left(\mathrm{Fe}^{3+}\right)$ and cupric ions $\left(\mathrm{Cu}^{2+}\right)$ reducing power, ferrous ions $\left(\mathrm{Fe}^{2+}\right)$ and cupric ions $\left(\mathrm{Cu}^{2+}\right)$ chelating activity, compared with the positive controls Trolox or BHT.

Results: In all assays, PCA along with positive controls exhibited dose-dependently antioxidant ability. Comparing to a standard antioxidant Trolox, the relative antioxidant activity of PCA (i.e. the ratio of $\mathrm{IC}_{50 \text { (Trolox) }} / \mathrm{IC}_{50(\mathrm{PCA})}$ ) was calculated as $2.8,2.3,3.7,6.1,4.2$, $1.0,2.7,1.5$, respectively, for DPPH, ABTS, reducing power $\left(\mathrm{Fe}^{3+}\right)$, reducing power $\left(\mathrm{Cu}^{2+}\right)$, superoxide anion radical-scavenging, hydroxyl radical-scavenging, chelating ability $\left(\mathrm{Fe}^{2+}\right)$ and chelating ability $\left(\mathrm{Cu}^{2+}\right)$. 
Conclusion: Comparing to Trolox, PCA shows much more effective antioxidant activity in vitro in both lipid and aqueous media. Hence, it could therefore be used in pharmacological or food industry as a natural antioxidant. It may exhibit antioxidant activity by both chelating metal transition ions as well as by scavenging free radicals via donating hydrogen atom $(\mathrm{H} \bullet)$ or electron (e).

Keywords: Protocatechuic acid, antioxidant, reducing power, free radical-scavenging, chelating ability.

\section{Background:}

It has been well recognized that, many biochemical reactions involve the generation of ROS (reactive oxygen species) in our body. However, under normal conditions, the balance between the generation and diminution of ROS is controlled by the antioxidant defense system. Under certain pathological conditions, when ROS are not effectively eliminated by the antioxidant defense system, the dynamic balance between the generation and diminution of ROS is broken. Excessive ROS attack lipids, carbohydrates, proteins, DNA, and result in oxidative stress, that leads to various disorders and diseases [1]. In order to protect biomolecules against the attack of ROS and/or to suppress the resultant damage, synthetic antioxidants have been used for industrial processing in recent years. However, these synthetic antioxidants have been suspected of being harmful to liver [2]. Thus, considerable focus has been given to searching for natural antioxidants from plants especially traditional Chinese herbal medicines in recent years.

As a natural phenolic acid, protocatechuic acid (PCA, 3,4-dihydroxybenzoic acid) is widely distributed in many traditional Chinese herbal medicines, such as Stenoloma chusanum (L.) Ching, Ilex chinensis Sims, Cibotium barometz (L.) J.Sm, and is regarede as an active component of these Chinese herbal medicines. Morever, PCA was reported to possess various pharmacological effects which may be closely correlated with its antioxidant activities [3] [4] [5] [6]. However, the antioxidant of PCA has not been investigated systematically yet.

Therefore, in the present work, the antioxidant activity and antioxidant mechanism of protocatechuic acid was clarified using various in vitro antioxidant assays including 1,1-diphenyl-2-picryl-hydrazyl (DPPH•), 2,2'-azino-bis(3-ethylbenzthiazoline-6-sulfonic acid) (ABTS), and superoxide anion radicals $\left(\bullet \mathrm{O}_{2}{ }^{-}\right)$and hydroxyl radicals scavenging activity, ferric ions $\left(\mathrm{Fe}^{3+}\right)$ and cupric ions $\left(\mathrm{Cu}^{2+}\right)$ reducing power, ferrous ions $\left(\mathrm{Fe}^{2+}\right)$ and cupric ions $\left(\mathrm{Cu}^{2+}\right)$ chelating activity.

\section{Materials:}

Protocatechuic acid (IUPAC name: 3,4-dihydroxybenzoic acid, CAS number: 99-50-3, >99\%) 
was obtained from NICPBP (National Institute for the Control of Pharmaceutical and Biological Products, China); DPPH• (1,1-Diphenyl-2-picrylhydrazyl radical), pyrogallol, linoleic acid, Trolox ( \pm -6-hydroxyl-2,5,7,8-tetramethlychromane-2-carboxylic acid), Ferrozine [3-(2-pyridyl)-5,6-bis (4-phenylsulfonicacid)-1,2,4-triazine], neocuproine (2,9-dimethyl-1,10-phenanthroline), BHA (butylated hydroxyanisole), BHT (butylatedhydroxy-toluene) and murexide (5,5'-nitrilodibarbituric acid monoammonium salt) were purchased from Sigma Co.; ABTS diammonium salt [2,2'-Azino-bis (3-ethylbenzothiazoline-6-sulfonic acid diammonium salt)], and D-2-deoxyribose were obtained from Amresco Co.; All other chemicals were of analytic grade.

\section{Methods:}

\section{$D P P H \cdot$ scavenging activity}

DPPH radical-scavenging activity was determined as described [3]. Briefly, $1 \mathrm{~mL}$ of DPPH• solution $(0.1 \mathrm{mmol} / \mathrm{L})$ was mixed with $0.5 \mathrm{~mL}$ of various concentrations of samples dissolved in $95 \%$ ethanol. The mixture was kept at room temperature for $30 \mathrm{~min}$, and then the absorbance at $519 \mathrm{~nm}$ was measured on spectrophotometer (Unico 2100, Shanghai, China), using 95\% ethanol as the blank. Trolox and BHT were used as the positive controls, and the percentage $\mathrm{DPPH} \bullet$ inhibition of the test samples was calculated:

$$
\text { Inhibition } \%=\left(1-A_{\mathrm{S}} / A_{0}\right) \times 100
$$

Where $A_{S}$ is the absorbance in the presence of the sample protocatechuic acid or positive controls, while $\mathrm{A}_{0}$ is the absorbance in the absence of the sample protocatechuic acid and positive controls.

\section{ABTS $^{+} \cdot$ scavenging activity}

The scavenging activity of $\mathrm{ABTS}^{+} \bullet$ was measured by the method [3]. The $\mathrm{ABTS}^{+} \bullet$ was produced by mixing $0.35 \mathrm{~mL}$ of ABTS diammonium salt $(7.4 \mathrm{mmol} / \mathrm{L})$ with $0.35 \mathrm{~mL}$ of potassium persulfate $(2.6 \mathrm{mmol} / \mathrm{L})$. The mixture was kept in the dark at room temperature for $12 \mathrm{~h}$ to allow completion of radical generation, and then diluted with $95 \%$ ethanol (about 1:50) so that its absorbance at $734 \mathrm{~nm}$ was $0.70 \pm 0.02$ measured on a spectrophotometer (Unico 2100, Shanghai, China). To determine the scavenging activity, $1.2 \mathrm{~mL}$ of $\mathrm{ABTS}^{+} \cdot$ reagent was mixed with $0.3 \mathrm{~mL}$ of sample or negative control (95\% ethanol), and the absorbance at $734 \mathrm{~nm}$ was measured at 6 min after the initial mixing, using $95 \%$ ethanol as the blank. The percentage inhibition of the samples was calculated as:

$$
\text { Inhibition } \%=\left(1-A / A_{0}\right) \times 100
$$


Where $A_{0}$ is the absorbance at $734 \mathrm{~nm}$ of the negative control, $A$ is the absorbance at 734 $\mathrm{nm}$ of the mixture with sample. Trolox and BHT, with a final concentration range of $0.67-2.67$ $\mu \mathrm{g} / \mathrm{mL}$, were prepared as positive controls.

\section{Ferric ions $\left(\mathrm{Fe}^{3+}\right)$ reducing power}

Ferric cyanide $\left(\mathrm{Fe}^{3+}\right)$ reducing power was determined by the method of Oyaizu et al. [14], as described by $\mathrm{Li}$ et al [3]. Samples $(x \mu \mathrm{L})$ at various concentrations were mixed with $\mathrm{Na}_{2} \mathrm{HPO}_{4} / \mathrm{KH}_{2} \mathrm{PO}_{4}$ buffer (350- $\left.x \mu \mathrm{L}, 0.2 \mathrm{~mol} / \mathrm{L}, \mathrm{pH} 6.6\right)$ and $\mathrm{K}_{3} \mathrm{Fe}(\mathrm{CN})_{6}(250 \mu \mathrm{L}, 1 \mathrm{~g} / 100 \mathrm{~mL})$. The mixture was incubated at $50{ }^{\circ} \mathrm{C}$ for $20 \mathrm{~min}, 250 \mu \mathrm{L}$ of trichloroacetic acid $(10 \mathrm{~g} / 100 \mathrm{~mL})$ was added, and the mixture was centrifuged at $3500 \mathrm{~g}$ for $10 \mathrm{~min}$. The supernatant $(400 \mu \mathrm{L})$ was recovered, mixed with distilled water $(400 \mu \mathrm{L})$ and $\mathrm{FeCl}_{3}(400 \mu \mathrm{L}, 0.1 \mathrm{~g} / 100 \mathrm{~mL})$ and placed immediately into the spectrophotometer (Unico 2100, Shanghai, China), and the timer was started. The absorbance at $700 \mathrm{~nm}$ was measured at $90 \mathrm{~s}$. Samples were analyzed in groups of three, and when the analysis of one group has finished, the next group of three samples were mixed with $\mathrm{FeCl}_{3}$ to avoid oxidization by air. Trolox and BHT were used as the positive controls, and an increased absorbance reading indicated increased reducing power. The percentage reducing power of the sample as compared to the maximum absorbance tested which appeared in protocatechuic acid at $10 \mu \mathrm{g} / \mathrm{mL}$ was calculated by using the formula: $\left(A_{\mathrm{S}}\right.$ $\left./ A_{\mathrm{m}}\right) \times 100$. Here, $A_{\mathrm{m}}=$ absorbance of maximum absorbance tested and $A_{\mathrm{S}}=$ absorbance of sample.

\section{Cupric ions $\left(\mathrm{Cu}^{2+}\right)$ reducing power}

In order to further measure the reducing ability of protocatechuic acid, the cupric ions $\left(\mathrm{Cu}^{2+}\right)$ reducing power capacity was also used with slight modification [15]. Briefly, $250 \mu \mathrm{L} \mathrm{CuSO}_{4}$ aqueous solution (10 mmol/L), $250 \mu \mathrm{L}$ neocuproine ethanolic solution $(7.5 \mathrm{mmol} / \mathrm{L})$ and 250 $\mu \mathrm{L} \mathrm{CH}_{3} \mathrm{COONH}_{4}$ buffer solution (100 mmol/L, $\mathrm{pH}$ 7.0) were added to a test tube containing a protocatechuic acid sample. Then, the total volume was adjusted with the buffer to $2 \mathrm{~mL}$ and mixed vigorously. Absorbance against a buffer blank was measured at $450 \mathrm{~nm}$ after $30 \mathrm{~min}$. Increased absorbance of neocuproine- $\mathrm{Cu}^{+}$complex in the reaction mixture indicates increased reduction capability. Trolox and BHA were used as the positive controls. The percentage reducing power of the sample as compared to the maximum absorbance tested which appeared in protocatechuic acid at $6 \mu \mathrm{g} / \mathrm{mL}$ was calculated by using the formula: $\left(A_{\mathrm{S}} / A_{\mathrm{m}}\right) \times 100$. Here, $A_{\mathrm{m}}=$ absorbance of maximum absorbance tested and $A_{\mathrm{S}}=$ absorbance of sample.

\section{Superoxide anion $\left(\cdot \mathrm{O}_{2}{ }^{-}\right)$scavenging activity}

The scavenging ability at $\mathrm{pH} 8.2$ of all test samples was determined by the method of Marklund and Marklund [16], as described by Li et al [3]. Briefly, samples were dissolved in suitable solvents (absolute or $95 \%$ ethanol) at a concentration of $5 \mathrm{mg} / \mathrm{mL}$. The sample solution $(x \mu \mathrm{L}$, where $x=0,30,60,90,120,150$, or $180 \mu \mathrm{L})$ was mixed with Tris-HCl buffer $(2920-x \mu \mathrm{L}, 0.05$ $\mathrm{mol} / \mathrm{L}, \mathrm{pH} 8.2)$ containing EDTA ( $1 \mathrm{mmol} / \mathrm{L})$ and pyrogallol $(80 \mu \mathrm{L}, 6 \mathrm{mmol} / \mathrm{L})$, then shaken rapidly at room temperature. The absorbance at $325 \mathrm{~nm}$ of the mixture was measured (Unico 
2100, Shanghai, China) against the Tris- $\mathrm{HCl}$ buffer every $30 \mathrm{~s}$ for $5 \mathrm{~min}$. The slope of the correlation of absorbance with time was calculated. The reaction mixture without added sample was used as the control. The $\cdot \mathrm{O}_{2}{ }^{-}$scavenging ability was calculated as:

$$
(1-\text { Slope of sample/Slope of control) } \times 100 \%
$$

\section{Hydroxyl radical $(\bullet \mathrm{OH})$ scavenging activity}

The scavenging activity on the hydroxyl radical $(\cdot \mathrm{OH})$ was investigated by the deoxyribose method [17] modified with some modification. Our preliminary experiments demonstrated that almost organic solvents except for petroleum ether can promote the inhibition percentage value, including ethanol, methanol, acetone, ethyl acetate, acetonitrile, chloroform, diethyl ether, DMF, DMSO, and THF. Hence, the inhibition of hydroxyl radical was evaluated as the following procedure: all test samples were firstly dissolved in ethanol $(1 \mathrm{mg} / \mathrm{mL})$, and 5-40 $\mu \mathrm{L}$ sample solution was taken into mini tubes, the ethanol solvent was then removed at $80{ }^{\circ} \mathrm{C}$ to eliminate its interference. The reactions were performed in $0.2 \mathrm{~mol} / \mathrm{L}$ phosphate buffer $(\mathrm{Ph}$ 7.4), containing $2.8 \mathrm{mmol} / \mathrm{L}$ deoxyribose, $2.8 \mathrm{mmol} / \mathrm{L} \mathrm{H}_{2} \mathrm{O}_{2}, 25 \mu \mathrm{mol} / \mathrm{L} \mathrm{FeCl}{ }_{3}, 80 \mu \mathrm{mol} / \mathrm{L}$ $\mathrm{Na}_{2}$ EDTA, and the test sample $(5-40 \mu \mathrm{g})$. The reaction was started by adding ascorbic acid to a final concentration of $100 \mu \mathrm{mol} / \mathrm{L}$ and the reaction mixture $(600 \mu \mathrm{L}$ in total) was incubated for $20 \mathrm{~min}$ at $50{ }^{\circ} \mathrm{C}$ in a water bath. After incubation, the color was developed by addition of $0.5 \mathrm{~mL}$ 2-thiobarbituric acid $(1 \mathrm{~g} / 100 \mathrm{~mL})$ followed by $0.5 \mathrm{~mL}$ trichloroacetic acid $(5 \mathrm{~g} / 100$ $\mathrm{mL}$ ) and heating in a boiling water bath for $15 \mathrm{~min}$. The sample was cooled and diluted two-fold with $95 \%$ ethanol, and the absorbance was measured at $532 \mathrm{~nm}$ against buffer (as blank). The reaction mixture without sample was used as control. The scavenging activity on hydroxyl radicals was expressed as:

$$
\text { Inhibition } \%=\left(1-A / A_{0}\right) \times 100
$$

Where $A_{0}$ is the absorbance at $532 \mathrm{~nm}$ of control (without sample), and $A$ is the absorbance at $532 \mathrm{~nm}$ of the reaction mixture containing sample. Trolox and BHT were taken as positive controls.

\section{Chelating activity on $\mathrm{Fe}^{2+}$}

The chelating abilities on $\mathrm{Fe}^{2+}$ by protocatechuic acid and positive controls were estimated by the method as described by Gülçin [18]. Briefly, 1mg/mL protocatechuic acid solution (200, $400,600 \mu \mathrm{L})$ was added to a solution of $250 \mu \mathrm{mol} / \mathrm{L} \mathrm{FeCl}_{2}(100 \mu \mathrm{L})$. The reaction was initiated by the addition of $250 \mu \mathrm{mol} / \mathrm{L}$ Ferrozine $(150 \mu \mathrm{L})$. The total volume of the systems was adjusted to $1000 \mu \mathrm{L}$ with methanol. Then, the mixture was shaken vigorously and left at room temperature for $10 \mathrm{~min}$. Absorbance of the solution was then measured spectrophotometrically at $562 \mathrm{~nm}$ (Unico 2100, Shanghai, China). The percentage of chelating effect was calculated by using the formula given bellow: 
Ferrous chelating effect $(\%)=\left(1-\mathrm{A} / \mathrm{A}_{0}\right) \times 100$

Where $\mathrm{A}$ is the absorbance in the presence of the sample protocatechuic acid or positive controls, while $A_{0}$ is the absorbance in the absence of the sample protocatechuic acid and positive controls.

\section{Chelating activity on $\mathrm{Cu}^{2+}$}

The chelating activity on $\mathrm{Cu}^{2+}$ of protocatechuic acid and positive controls was estimated by a complexometric method using murexide [19]. Briefly, to hexamine $\mathrm{HCl}$ buffer ( $\mathrm{pH} 5.0,30$ $\mathrm{mmol} / \mathrm{L})$ containing $30 \mathrm{mmol} / \mathrm{L} \mathrm{KCl}$ and $0.3 \mu \mathrm{mol}$ murexide, $60 \mu \mathrm{L} \mathrm{CuSO}_{4}(20 \mathrm{mmol} / \mathrm{L})$ was added. After incubation for $1 \mathrm{~min}$ at room temperature, the reaction was initiated by the addition of $10 \mathrm{mg} / \mathrm{mL}$ protocatechuic acid ethanolic solution $(5,15,25,35,45 \mu \mathrm{L})$. The total volume of the systems was adjusted to $1000 \mu \mathrm{L}$ with methanol. Then, the mixture was shaken vigorously and left at room temperature for $10 \mathrm{~min}$. Absorbance of the solution was then measured spectrophotometrically at 485 and $520 \mathrm{~nm}$ (Unico 2100, Shanghai, China).The absorbance ratio $\left(\mathrm{A}_{485} / \mathrm{A}_{520}\right)$ reflected the free $\mathrm{Cu}^{2+}$ content. Therefore, the percentage of cupric chelating effect was defined as follows:

Cupric chelating effect $(\%)=\left[\left(\mathrm{A}_{485} / \mathrm{A}_{520}\right)_{\max }-\left(\mathrm{A}_{485} / \mathrm{A}_{520}\right)\right] /\left(\mathrm{A}_{485} / \mathrm{A}_{520}\right)_{\max } \times 100$

Where $\left(\mathrm{A}_{485} / \mathrm{A}_{520}\right)$ is the absorbance ratio in the presence of the samples, while $\left(\mathrm{A}_{485} / \mathrm{A}_{520}\right)$ $\max$ is the maximum absorbance ratio without any samples. Sodium citrate and Tolox were used as the positive controls.

\section{Statistical analysis:}

Data are given as the mean $\pm \mathrm{SD}$ of three measurements. The $\mathrm{IC}_{50}$ values were calculated by linear regression analysis. All linear regression in this paper was analyzed by Origin 6.0 professional software.

\section{Results and Discussion:}

\section{$D P P H \bullet$ and $A B T S^{+} \bullet$ scavenging activity}

DPPH and ABTS assays have been widely used to determine the free radical-scavenging activity of various pure compounds or extracts. Both DPPH and ABTS are stable free radicals which dissolve in methanol or ethanol, and their colors show characteristic absorptions at 519 $\mathrm{nm}$ or $734 \mathrm{~nm}$, respectively. When an antioxidant scavenges the free radicals by hydrogen donation, the colors in the DPPH and ABTS assay solutions become lighter. As presented in Fig.1, both the $\mathrm{DPPH} \bullet$ and $\mathrm{ABTS}^{+} \bullet$ inhibition percentage values were dose dependent where it 
increased in the range of the tested concentration, for protocatechuic acid and the positive controls Trolox and BHT. DPPH radical inhibition decreased in the order protocatechuic acid $>\mathrm{BHT} \approx$ Trolox, while ABTS radical ion inhibition in the order protocatechuic acid > BHT > Trolox. The $\mathrm{DPPH} \bullet$ and $\mathrm{ABTS}^{+} \cdot \mathrm{IC}_{50}$ values $\left(\mathrm{IC}_{50}\right.$ value is the concentration of the sample required to inhibit $50 \%$ of radical) of protocatechuic acid, Trolox and BHT were calculated and listed in Table 1.
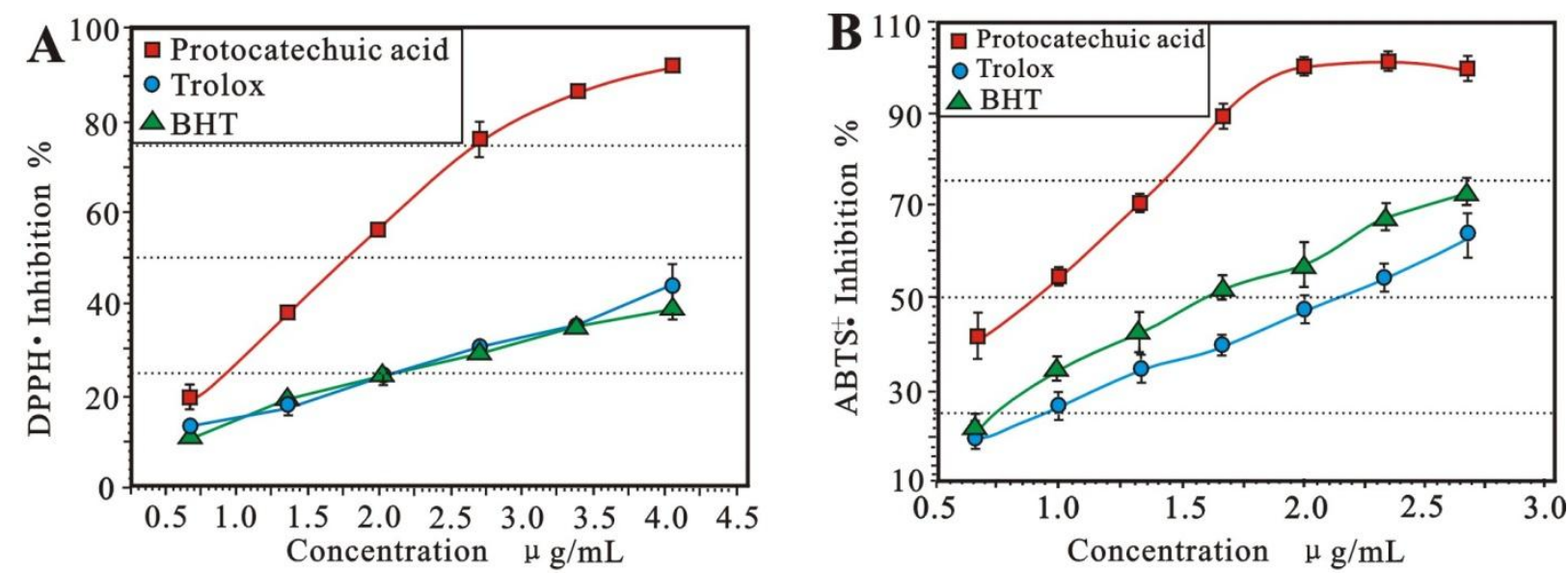

Figure 1. Effect of different concentration of protocatechuic acid in free radical scavenging tests: (A) DPPH assay, (B) ABTS assay. Each value is expressed as mean \pm standard deviation, $\mathrm{n}=3$.

It is proposed that $\mathrm{DPPH} \cdot$ may be scavenged by an antioxidant through donation of hydrogen atom $(\mathrm{H} \bullet)$ to form a stable DPPH-H molecule which does not absorb at 519nm [7]. According to this hypothesis and previous study [8], the reaction between DPPH $\bullet$ and PCA could be explained by the following mechanism:

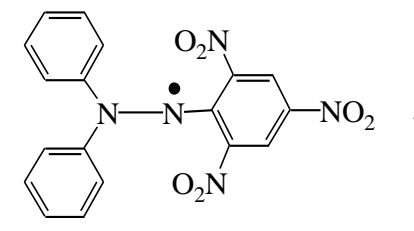

$\mathrm{DPPH} \bullet$<smiles>O=C(O)c1ccc(O)c(O)c1</smiles>

PCA<smiles>CCCCCCCCC(=O)c1ccc(O)c(O)c1</smiles>

(A)<smiles>O=[N+]([O-])c1cc([N+](=O)[O-])c(NN(c2ccccc2)c2ccccc2)c([N+](=O)[O-])c1</smiles>

DPPH-H

Radical (A) can be further withdrawn hydrogen atom $(\mathrm{H} \bullet)$ to form stable quinone (B).<smiles>CCCCCCC(=O)O</smiles>

(A)<smiles>O=C1C=CC(=O)C(=O)C1</smiles>

(B) 
However, the scavenging of $\mathrm{ABTS}^{+} \bullet$ is assumed to be an electron transfer process:

$$
\text { ABTS }^{+}+\mathrm{e} \longrightarrow \text { ABTS }
$$

$\mathrm{ABTS}^{+} \cdot$ can be previously produced by the reaction between ABTS diammonium salt and potassium persulfate:

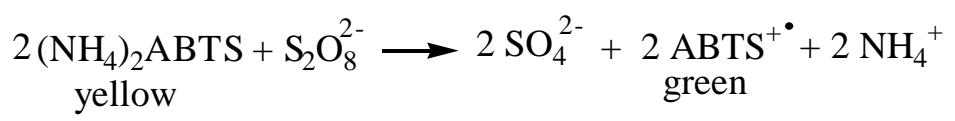

Our results indicating that PCA can effectively inhibit $\mathrm{DPPH} \bullet$ and $\mathrm{ABTS}^{+} \bullet$, suggested that PCA exerted radical-scavenging action by donating hydrogen atom $(\mathrm{H} \bullet)$ and electron $(\mathrm{e})$.

\section{Reducing power assay}

Although a reductant is not necessarily an antioxidant, an antioxidant is commonly a reductant [9]. The reducing power of a compound may therefore serve as a significant indicator of its potential antioxidant activity [10]. It can be seen that the reducing power percentage values of protocatechuic acid and the positive controls were concentration related and increased with the increasing of sample concentration in the range of the tested concentration (Fig. 2). Their relative reducing powers on $\mathrm{Fe}^{3+}$ were as follows: protocatechuic acid $>$ Trolox $\approx$ BHT, while the relative reducing powers on $\mathrm{Cu}^{2+}$ were protocatechuic acid > BHA > Trolox. The $\mathrm{IC}_{50}$ values of all tested samples were calculated and listed in Table 1.
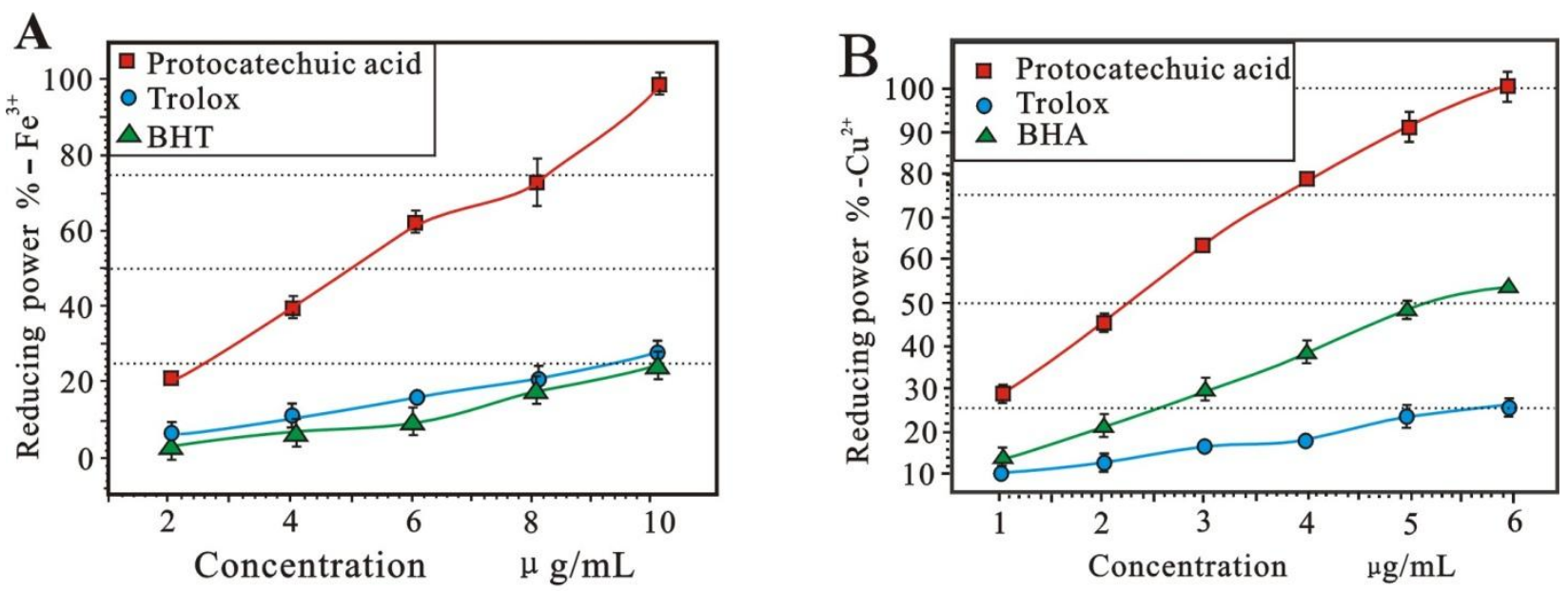

Figure 2. Reducing power assays of protocatechuic acid and positive controls: (A) $\mathrm{Fe}^{3+} \rightarrow \mathrm{Fe}^{2+}$; (B) $\mathrm{Cu}^{2+} \rightarrow \mathrm{Cu}^{+}$. Each value is expressed as mean \pm standard deviation, $\mathrm{n}=3$.

Protocatechuic acid was demonstrated to be a more effective reductant than the standard antioxidants in both reducing power assays $\left(\mathrm{Fe}^{3+} \rightarrow \mathrm{Fe}^{2+}\right.$ and $\left.\mathrm{Cu}^{2+} \rightarrow \mathrm{Cu}^{+}\right)$. The results are obviously consistent with the total antioxidant activity in DPPH and ABTS assays.

\section{Superoxide anion $\left(\bullet^{\left.\mathrm{O}_{2}-\right)}\right.$ and hydroxyl $(\bullet \mathrm{OH})$ radical-scavenging activity}

ROS are various forms of activated oxygen including free radicals and non-free-radical species. Superoxide anion $\left(\cdot \mathrm{O}_{2}{ }^{-}\right)$and hydroxyl radical $(\bullet \mathrm{OH})$ are two of the most important free 
radicals in living cells. Superoxide anion, arising either through metabolic processes or following oxygen "activation" by physical irradiation, is considered the "primary" ROS, and can further interact with other molecules to generate "secondary" ROS, either directly or prevalently through enzyme- or metal-catalyzed processes. Hydroxyl radical $(\bullet \mathrm{OH})$, however, as the most dangerous form of ROS, has a high reactivity with a very short half-life of approx. $10^{-9} \mathrm{~s}$ in vivo [11].

In our experiments, the superoxide radical was generated by the pyrogallol system at $\mathrm{pH}$ 8.2. Fig. 3A showed that PCA and the positive controls (Trolox and BHT) demonstrated an ability to inhibit superoxide anion in a dose-dependent manner. PCA exhibited higher inhibition level than Trolox at the tested concentration, but lower than BHT. Their $\mathrm{IC}_{50}$ values were calculated and listed in Table 1 . The hydroxyl $(\bullet \mathrm{OH})$ radical-scavenging activity was evaluated by the Fenton reaction using the deoxyribose assay. In this study, a mixture of $\mathrm{Fe}^{3+}$-EDTA, hydrogen peroxide $\left(\mathrm{H}_{2} \mathrm{O}_{2}\right)$, and ascorbic acid were used to generate hydroxyl radicals $(\cdot \mathrm{OH})$. The response degrades D-2-deoxyribose into fragments which under heating with thiobarbituric acid at acidic solution, are detected at 540nm because they generate a pink chromogen. The data in Fig. 3B showed that PCA and the positive controls could effectively inhibit the formation of $\bullet \mathrm{OH}$ generated in a concentration-dependent manner. According to the $\mathrm{IC}_{50}$ values (Table 1), PCA possessed the similar scavenging activity to Trolox, but lower than BHT.
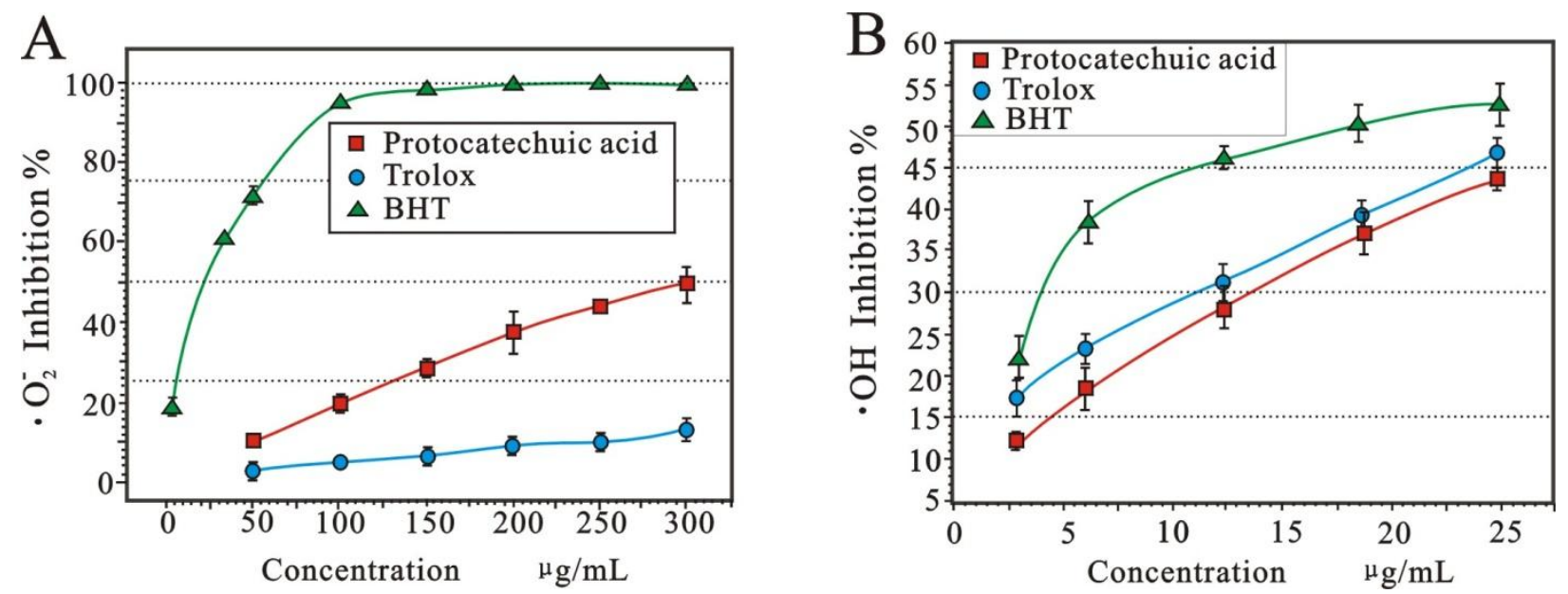

Figure 3. Superoxide anion (A) and hydroxyl (B) radical scavenging activity of protocatechuic acid, Trolox and BHT. Each value is expressed as mean \pm standard deviation, $n=3$.

\section{Metal ions chelating activity}

Actually, hydroxyl radical can be generated by the Fenton reaction $\left(\mathrm{Fe}^{2+}+\mathrm{H}_{2} \mathrm{O}_{2} \rightarrow \mathrm{Fe}^{3+}+\cdot \mathrm{OH}\right.$ $+\mathrm{OH}^{-}$), in which iron participates as a catalyst in body. The superoxide radical participates in the Haber-Weiss reaction $\left(\cdot \mathrm{O}_{2}{ }^{-}+\mathrm{H}_{2} \mathrm{O}_{2} \rightarrow \mathrm{O}_{2}+\cdot \mathrm{OH}+\mathrm{OH}^{-}\right)$which combines a Fenton reaction and the reduction of $\mathrm{Fe}^{3+}$ by superoxide, yielding $\mathrm{Fe}^{2+}$ and oxygen $\left(\mathrm{Fe}^{3+}+\cdot \mathrm{O}_{2}^{-} \rightarrow \mathrm{Fe}^{2+}\right.$ 
$+\mathrm{O}_{2}$ ). As ferrous ion and other transition metal ions (e.g. $\mathrm{Cu}^{2+}$ ) can catalyze the oxidation in body, it is significant to investigate the metal chelating activity of an antioxidant.

The data in Fig. 4 revealed that the metal chelating activity of PCA and the positive controls were concentration-dependent. As can be seen in Fig. 4A, PCA showed the distinctly higher chelating activity on $\mathrm{Fe}^{2+}$ than Trolox and BHT, however, its chelating activity on $\mathrm{Cu}^{2+}$ is lower than sodium citrate which is regarded as a strong chelating agent in chemical industry (Fig. 4B). Generally, compounds with structures containing two or more of the following functional groups: $-\mathrm{OH},-\mathrm{SH},-\mathrm{COOH},-\mathrm{PO}_{3} \mathrm{H}_{2}, \mathrm{C}=\mathrm{O},-\mathrm{NR}_{2},-\mathrm{S}-$ and $-\mathrm{O}-$ in a favorable structure-function configuration will have chelating activity [12].
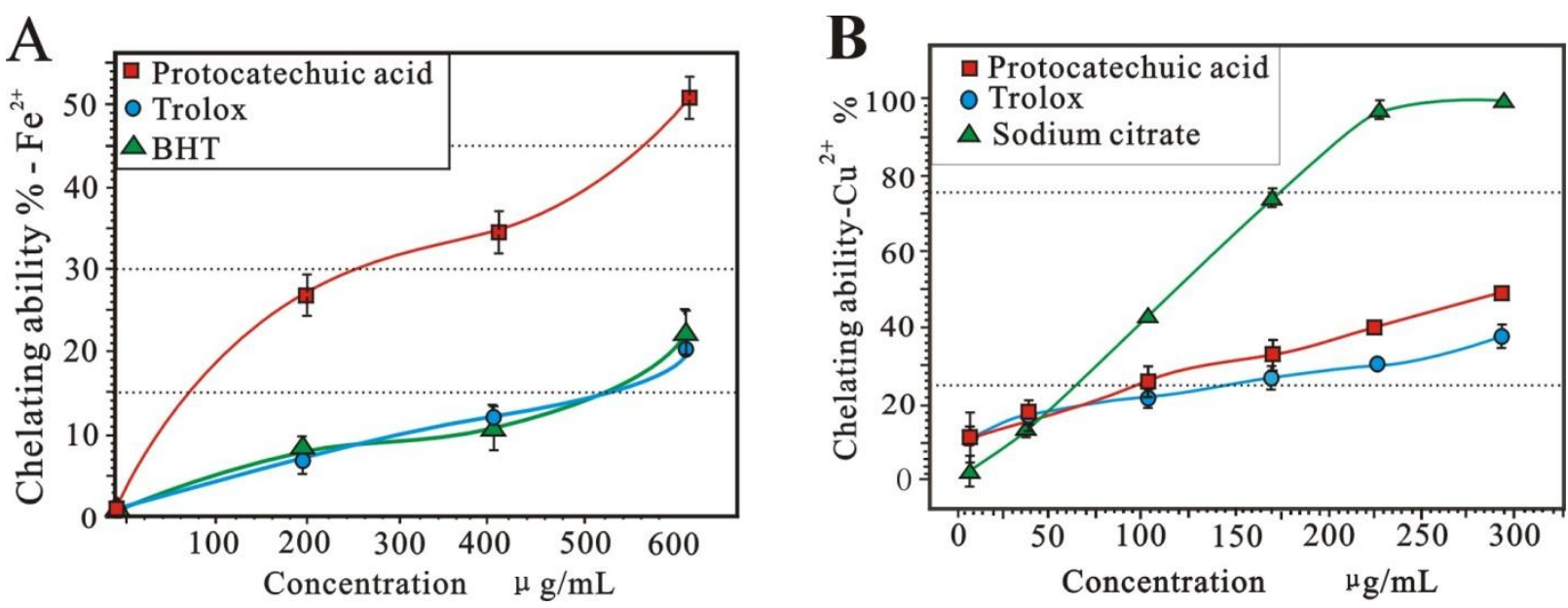

Figure 4. Metal chelating ability of protocatechuic acid, Trolox and BHT: (A) $\mathrm{Fe}^{2+}$, (B) $\mathrm{Cu}^{2+}$. Each value is expressed as mean \pm standard deviation, $\mathrm{n}=3$.

Hence, this metal chelating activity may arise from the ortho-dihydroxyl groups in PCA molecule. The proposed reaction of PCA binding for $\mathrm{Fe}^{2+}$ is given in the following:<smiles>CC[C+]#[P+]CC</smiles>

Recently, Torreggiani et al. demonstrated that quercetin-chelated metal ions in the same way [13]. These results also suggested that PCA exhibits antioxidant activity maybe by both chelating metal transition ions as well as by scavenging free radicals. Undoubtedly, PCA's various pharmacological activities mentioned above are closely correlated with its antioxidant activities.

In the present study, DPPH, ABTS and chelating ability $\left(\mathrm{Fe}^{2+}\right)$ assays were conducted in organic solutions, while reducing power $\left(\mathrm{Fe}^{3+} \& \mathrm{Cu}^{2+}\right)$, superoxide anion and hydroxyl radical-scavenging, and chelating ability $\left(\mathrm{Cu}^{2+}\right)$ assays in aqueous solutions. Our results 
showed that PCA exhibited dose-dependently significant antioxidant abilities in both lipid and aqueous mediums. Thus, PCA is regarded as an ideal natural antioxidant in both mediums.

Table 1 The values of $\mathrm{IC}_{50}(\mu \mathrm{g} / \mathrm{mL})$

\begin{tabular}{c|ccccccccc}
\hline & & \multicolumn{9}{|c}{ Reducing power } & & \multicolumn{2}{c}{ Chelating } \\
\cline { 5 - 6 } \cline { 7 - 9 } & DPPH & ABTS & $\mathrm{Fe}^{3+}$ & $\mathrm{Cu}^{2+}$ & $\mathrm{O}_{2}^{-}$ & $\bullet \mathrm{OH}$ & $\mathrm{Fe}^{2+}$ & $\mathrm{Cu}^{2+}$ \\
PCA & 1.88 & 0.89 & 5.15 & 2.25 & 310.28 & 74.11 & 566 & 312.34 \\
Trolox & 5.28 & 2.08 & 19.04 & 13.78 & 1289.30 & 70.51 & 1520 & 467.40 \\
BHT & 5.75 & 1.66 & 20.62 & $5.46^{\mathrm{a}}$ & 28.21 & 46.67 & 1440 & $118.53^{\mathrm{b}}$ \\
\hline
\end{tabular}

${ }^{\mathrm{a}}$ BHA $\quad{ }^{\mathrm{b}}$ Sodium citrate

To further evaluate the antioxidant property of PCA, the $\mathrm{IC}_{50}$ values were assessed in Table 1 . The $\mathrm{IC}_{50}$ values of PCA were generally lower than of the positive controls, suggesting that PCA is a better antioxidant than the positive controls, as the lower $\mathrm{IC}_{50}$ value reflects the higher antioxidant activity. Among the positive controls, Trolox is considered as the most common standard antioxidant, and the relative antioxidant ability of PCA comparing to Trolox has therefore been defined as the ratio of $\mathrm{IC}_{50 \text { (Trolox) }} / \mathrm{IC}_{50(\mathrm{PCA})}$. The ratio values were calculated as $2.8,2.3,3.7,6.1,4.2,1.0,2.7,1.5$, respectively for DPPH, ABTS, reducing power $\left(\mathrm{Fe}^{3+}\right)$, reducing power $\left(\mathrm{Cu}^{2+}\right)$, superoxide anion radical-scavenging, hydroxyl radical-scavenging, chelating ability $\left(\mathrm{Fe}^{2+}\right)$ and chelating ability $\left(\mathrm{Cu}^{2+}\right)$ assays (Fig. 5)

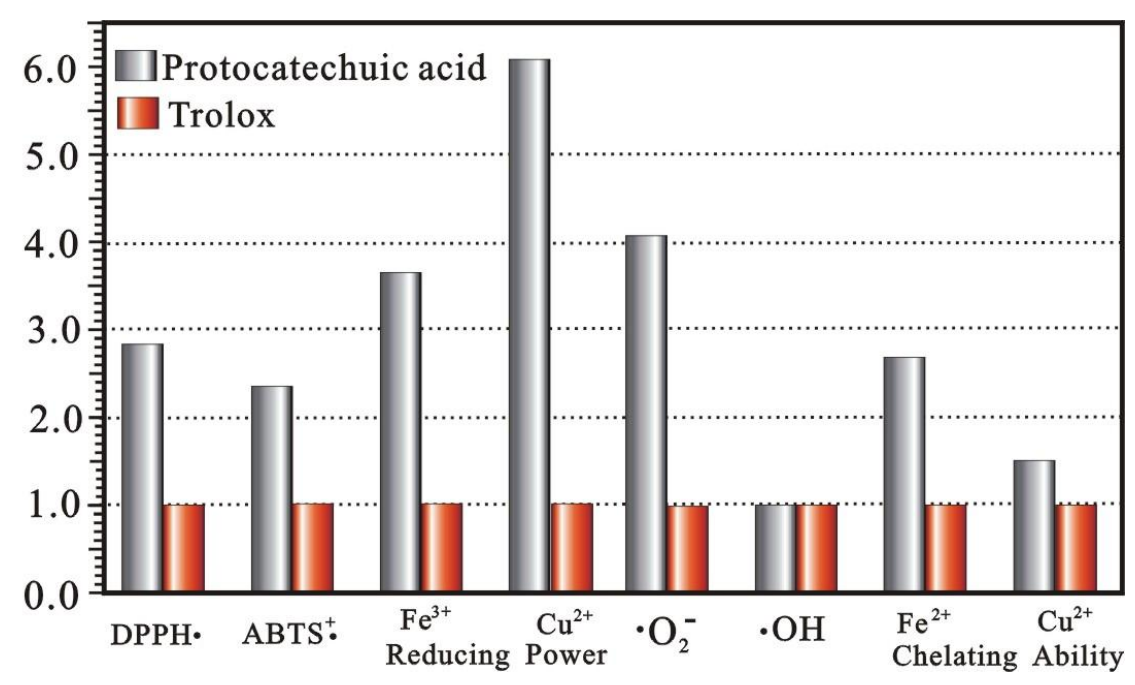

Figure 5. Relative antioxidant abilities of PCA comparing to Trolox

\section{Conclusion:}

In conclusion, protocatechuic acid was proved to be much more effective than Trolox in the comprehensive evaluation of antioxidant activity in vitro in both lipid and aqueous mediums, 
hence, it may therefore be used in pharmacological or food industry as natural antioxidant. It may exert antioxidant action in vitro by both chelating metal ions, and scavenging free radicals via donating hydrogen atom $(\mathrm{H} \bullet)$ or electron $(\mathrm{e})$.

\section{Competing interests:}

The authors declare that there are no competing interests.

\section{Author's Contributions:}

Xican $\mathrm{Li}$ is the principle investigator for this study providing oversight and contributed fundamental conceptualization for the research, writing a grant proposal and manuscript. Xiaozhen Wang performed the experiments and provided statistical analysis.

Dongfeng Chen is the research coordinator for the study and assisted in designing the study. Shuzhi Chen coordinated the research and assisted in performing the experiments.

All authors read and approved the final manuscript.

\section{Abbreviations:}

PCA : Protocatechuic acid; ABTS: 2, 2'-azino-bis(3-ethylbenzthiazoline-6-sulfonic acid); DPPH: 1,1-diphenyl-2-picryl-hydrazyl; ROS: reactive oxygen species; Trolox: ( \pm )-6 -hydroxyl -2,5, 7, 8-tetramethlychromane-2-carboxylic acid; BHT: butylatedhydroxy-toluene; BHA: butylated hydroxyanisole.

\section{Acknowledgements:}

This work was supported by National Nature Science Foundation of China (30772861).

\section{References:}

1. Zhao XY, Sun HD, Hou AJ, Zhao QS, Wei TT, Xin WJ. Antioxidant properties of two gallotannins isolated from the leaves of Pistacia weinmannifolia. BBA-Gen-Subjects. 2005; 1725:103-110.

2. Grice HC. Safety evaluation of butylated hydroxyanisole from the perspective of effects on forestomach and oesophageal squamous epithelium. Food and Chemical Toxicology. 1988; 26(8):717-723.

3. Shi GF, An LJ, Jiang B, Guan S, Bao YM. Alpinia protocatechuic acid protects against oxidative damage in vitro and reduces oxidative stress in vivo. Neuroscience Letters. 2006; 403(3):206-210.

4. Tanaka T, Tanaka T, Tanaka M. Potential Cancer Chemopreventive Activity of Protocatechuic Acid. Journal of Experimental \& Clinical Medicine. 2011; 3(1):27-33. 
5. Lin CY, Huang CS, Huang CY, Yin MC. Anticoagulatory, Antiinflammatory and Antioxidative Effects of Protocatechuic Acid in Diabetic Mice. Journal of Agricultural and Food Chemistry. 2009; 57(15):6661-6667.

6. Lee MJ, Chou FP, Tseng TH, Hsieh MH, Lin MC, Wang CJ. Hibiscus Protocatechuic Acid or Esculetin Can Inhibit Oxidative LDL Induced by Either Copper Ion or Nitric Oxide Donor. Journal of Agricultural and Food Chemistry. 2002; 50(7):2130-2136.

7. Bondet V, Brand-Williams W, Berset C. Kinetics and Mechanisms of Antioxidant Activity using the DPPH• Free Radical Method. Lebensmittel-Wissenschaft und-Technologie. 1997; 30:609-615.

8. Saito S, Kawabata J. Effects of electron-withdrawing substituents on DPPH radical scavenging reactions of protocatechuic acid and its analogues in alcoholic solvents. Tetrahedron. 2005; 61(34): 8101-8108.

9. Prior RL, Cao GH. In vivo total antioxidant capacity: comparison of different analytical methods. Free Radical Biology and Medicine. 1999; 27:1173-1181.

10. Jung MJ, Heo SI, Wang MH. Free radical scavenging and total phenolic contents from methanolic extracts of Ulmus davidiana. Food Chemistry. 2008; 108:482-487.

11. Valko M, Leibfritz D, Moncol J, Cronin MTD, Mazur M, Telse rJ. Free radicals and antioxidants in normal physiological functions and human disease. The International Journal of Biochemistry \& Cell Biology. 2007; 39:44-84.

12. Lindsay RC. Food additives. In O. R. Fennema (Ed.), Food chemistry, Marcel Dekker Inc. New York, USA, 1996; pp: 778-780.

13. Torreggiani A, Tamba M, Trinchero A, Bonora S. Copper (II)-Quercetin complexes in aqueous solutions: spectroscopic and kinetic properties. Journal of Molecular Structure. 2005; 744-747, 759-766.

14. Oyaizu M. Studies on product of browning reaction prepared from glucose amine. Japan Journal Nutrition. 1986; 44:307-315.

15. Gülçin, İ. Antioxidant properties of resveratrol: A structure-activity insight. Innovative Food Science and Emerging Technologies 2010;11(1):210-218.

16. Marklund S, Marklund G. Involvement of the superoxide anion radical in the autoxidation of pyrogallol and convenient assay for superoxide dismutase. Eur. J. Biochem. 1974; 47:469-474.

17. Kitts DD, Arosha NW, Chun H. Antioxidant properties of a North American ginseng extract. Mol. Cell. Biochem. 2000; 203:1-10.

18. Gülçin, İ. Antioxidant and antiradical activities of L-carnitine. Life Sciences. 2006; 78:803-811.

19. Blázovics A, Szentmihály iK, Lugasi A, Balázs A, Hagymási K, BányaiÉ, Then M, Rapavi E, Héthelyi É. In Vitro, Analysis of the Properties of Beiqishen Tea. Basic Nutritional Investigation 2003;19:869-875. 